\title{
Tuning Nanophase Separation Behavior in Segmented Polyhydroxyurethane via Judicious Choice of Soft Segment
}

\author{
Goliath Beniah ${ }^{\mathrm{a}}$, Brice E. Uno ${ }^{\mathrm{b}}$, Tian Lan ${ }^{\mathrm{c}}$, Junho Jeon ${ }^{\mathrm{d}}$, \\ William H. Heath ${ }^{\mathrm{d}}$, Karl A. Scheidt ${ }^{\mathrm{b}}$, and John M. Torkelson ${ }^{\mathrm{a}, c_{*}}$ \\ ${ }^{\mathrm{a}}$ Dept. of Chemical and Biological Engineering, Northwestern University, Evanston IL, 60208 USA \\ ${ }^{b}$ Dept. of Chemistry, Northwestern University, Evanston, IL 60208 USA \\ ${ }^{c}$ Dept. of Materials Science and Engineering, Northwestern University, Evanston, IL 60208 USA \\ ${ }^{d}$ The Dow Chemical Company, Freeport, TX 77541 USA \\ *Correspondence to: Prof. John M. Torkelson (Email: j-torkelson@ @orthwestern.edu)
}

\begin{abstract}
Polyhydroxyurethane (PHU) is of major research interest because it is a nonisocyanate polyurethane-like (NIPU) polymer. Here, we demonstrate the ability to tune nanophase separation in linear, segmented PHU copolymers via the soft segment. PHUs were synthesized from polytetramethylene oxide (PTMO)- and polybutadiene-co-acrylonitrile (PBN)based soft segments, with divinyl benzene dicyclocarbonate and Dytek-A as hard segment and chain extender, respectively. These NIPU polymers were characterized by small-angle X-ray scattering (SAXS), atomic force microscopy (AFM), dynamic mechanical analysis (DMA), differential scanning calorimetry (DSC), Fourier transform infrared spectroscopy (FTIR) and tensile testing. SAXS reveals that the NIPUs with 30-40 wt $\%$ hard segment are nanophase separated with interdomain spacings of 9-16 nm. DMA reveals that PTMO-based PHUs have broad interphases with a range of local compositions and glass transition temperatures $\left(T_{\mathrm{g}} \mathrm{s}\right)$, with $\tan \delta \geq 0.3$ over temperature ranges exceeding $70{ }^{\circ} \mathrm{C}$ in breadth. In contrast, PBN-based PHUs have sharper interphases, evidenced by narrow tan $\delta$ peaks near soft-segment and hard-segment $T_{\mathrm{g}} \mathrm{s}$ as well as by DSC and AFM data. FTIR shows that the ratio of hydrogen-bonded carbonyl to free carbonyl is higher in PBN-based PHU than in PTMO-based PHU, consistent with the absence and presence of intersegment hydrogen bonding in PBN-based PHU and PTMO-based PHU, respectively.
\end{abstract}

Keywords: non-isocyanate polyurethane, polyhydroxyurethane, segmented polyurethane, 
nanophase separation.

\section{INTRODUCTION}

Polyurethane (PU) is an important class of commodity polymer with wide-ranging applications [1-4]. It is produced from a step-growth reaction between isocyanates and alcohols with relatively fast reaction kinetics. There has been increasing regulatory scrutiny regarding the safe use, transport and handling of isocyanates, which has led to investigations into alternative chemistries to produce PU or PU-like materials without employing isocyanates [5-7]. Cyclic carbonate aminolysis resulting in polyhydroxyurethane (PHU) is a most promising chemistry to produce non-isocyanate polyurethane-like (NIPU) materials [8-12]. Although there have been many studies on single-phase PHUs, cross-linked PHUs, reaction catalysis, and cyclic carbonate synthesis [8-51], few studies have focused on segmented, nanophase-separated PHUs [52-55].

Segmented PU is a class of linear, multiblock copolymer composed of alternating sequences of soft and hard blocks. Depending on the block composition, segmented PU can exhibit properties ranging from those of soft elastomers to hard plastics while retaining the processing characteristics of thermoplastics. The soft blocks are typically long, flexible molecules with a glass transition temperature $\left(T_{\mathrm{g}}\right)$ below room temperature whereas the hard blocks, composed of diisocyanate condensed with small molecule diol, have a $T_{\mathrm{g}}$ above room temperature [56,57]. Segmented PUs typically exhibit excellent nanophase separation due to the incompatibility of soft and hard domains. The hydrogen bonding between polar urethane units reinforces the hard domain. Temperature-dependent dynamic mechanical studies of many segmented PUs show two stepwise transitions in storage modulus $\left(E^{\prime}\right)$ with two distinct peaks in $\tan \delta$ at temperatures related to the $T_{\mathrm{g}} \mathrm{s}$ of the soft and hard segments. This behavior is consistent with features observed in nanostructured block copolymers with a sharp interphase and in immiscible polymer blends. Varying degrees of nanophase separation are expected depending upon the structures of diisocyanate, soft segment, and chain extender employed in the synthesis of segmented PU as well as the overall material composition. 
Segmented PHUs with additional primary and secondary hydroxyl groups adjacent to the urethane linkages manifest very different nanophase separation behavior because of the ability of hard-segment hydroxyl groups to undergo intersegmental hydrogen bonding with hydrogen bond acceptors in the soft segment $[53,54]$. Torkelson and coworkers recently reported the synthesis and characterization of segmented PHUs using several polyether-based soft segments [53]. They showed that the hydroxyl groups caused major phase mixing in PHUs with polyethylene oxide (PEO)-based soft segment due to a high degree of intersegmental hydrogen bonding from the hard-segment hydroxyl groups to ether oxygen in the soft segment. This hydrogen bonding can be suppressed with polypropylene glycol (PPG)-based soft segments which sterically hinder access to the oxygen atoms and polytetramethylene oxide (PTMO)-based soft segments which dilute the oxygen atom content relative to PEO-based soft segments. Tunable mechanical properties can be achieved by the extent to which intersegemental hydrogen bonding is suppressed. In PTMO-based PHUs, the hydrogen bonding is partially suppressed but not eliminated [54]. This results in the formation of nanophase-separated PHU with broad interphases having a wide range of local compositions and potential application as broadtemperature-range damping materials [54,58]. Long and coworkers reported on segmented poly(amide-hydroxyurethane) systems composed of crystallizable hard segments and PTMObased soft segments [55]. They observed that phase mixing is dominant in nanophase-separated structures of such segmented PHUs. While the foregoing studies have successfully synthesized and characterized segmented PHUs, no study has yet demonstrated the ability to tune nanophase separation behavior in segmented PHU close to the level obtained in segmented PU.

The soft segment plays a critical role in controlling the degree of nanophase separation in segmented PUs [59-81]. Among many soft segments studied, polybutadiene-based soft segments have been reported to exhibit a very high degree of nanophase separation relative to those conferred by polyether- and polyester-based soft segments [66-76]. This result can be attributed to the non-polar nature of and the lack of hydrogen bond acceptor in polybutadiene-based soft segments, limiting hydrogen bonding to occur only within the hard segment. The suppression of 
intersegmental hydrogen bonding produces PU with a high degree of nanophase separation. Schneider and coworkers studied a segmented PU system composed of polybutadiene, toluene diisocyanate, and chain extenders [67-70]. Their differential scanning calorimetry (DSC) results showed that the soft-segment $T_{\mathrm{g}}$ is only slightly elevated from the $T_{\mathrm{g}}$ of pure polybutadiene softsegment starting material, with its value invariant with respect to PU hard-segment content. They attributed this effect to an almost complete segregation of hard and soft segments [67-70]. Similar observations were made by Boiteux and coworkers in other polybutadiene-based systems [71,72]. Chen-Tsai et al. studied several polybutadiene-based PU systems using small-angle Xray scattering (SAXS) [73]. They found that polybutadiene-based segmented PU possesses the lowest degree of interfacial mixing (highest degree of nanophase separation) as well as the sharpest domain interphase in comparison with polyether- and polyester-based segmented PUs.

Here, we demonstrate that segmented PHU exhibits significant tunability in nanophase separation behavior through judicious choice of soft segment. A series of PHUs were synthesized using PTMO- and polybutadiene-co-acrylonitrile (PBN)-based soft segments, with the latter strongly suppressing the potential for hydrogen bonding between hard and soft segments relative to the former. These PHUs were characterized by DMA, DSC, atomic force microscopy (AFM), FTIR and tensile testing. All PHUs synthesized in this study exhibit nanophase-separated structures in their bulk morphology via SAXS. The PTMO-based PHUs exhibit nanophase separation behavior characteristic of a material with broad interphases and thus a wide range of local compositions whereas the PBN-based PHUs exhibit nanophase separation with sharper domain interphases characteristic of nanophase-separated, isocyanate-based PUs and conventional block copolymer. FTIR reveals a higher proportion of hydrogen-bonded carbonyl in PBN-based PHUs than in PTMO-based PHUs, consistent with the absence and presence and presence of intersegment hydrogen bonding in PBN-based PHUs and PTMO-based PHUs, respectively. This study demonstrates that the choice of soft segment can significantly tune the state of nanophase separation in segmented PHUs, in some cases resulting properties that are qualitatively similar to those of nanophase-separated, isocyanate-based PUs. 


\section{EXPERIMENTAL}

\subsection{Materials}

Polybutadiene-co-acrylonitrile with 18 wt\% acrylonitrile (Hypro ${ }^{\mathrm{TM}}$ 1300X42 ATBN), subsequently referred to as PBN18, was supplied by Emerald Performance Materials® CVC Thermoset Specialties. It contains oligomers of Dytek-A-terminated polybutadiene-coacrylonitrile (18 wt\% acrylonitrile) with $M_{\mathrm{n}}=3800 \mathrm{~g} / \mathrm{mol}$ and excess Dytek-A. The amine equivalent weight is $427 \mathrm{~g} / \mathrm{mol}$. Polybutadiene-co-acrylonitrile with $10 \mathrm{wt} \%$ acrylonitrile, subsequently referred to as PBN10, is an experimental variant of Hypro ${ }^{\mathrm{TM}} 1300 \mathrm{X} 42$ ATBN. It contains oligomer of Dytek-A-terminated polybutadiene-co-acrylonitrile (10 wt $\%$ acrylonitrile) with $M_{\mathrm{n}}=3800 \mathrm{~g} / \mathrm{mol}$ and excess Dytek-A. The amine equivalent weight is $634 \mathrm{~g} / \mathrm{mol}$. Diamineterminated polytetramethylene oxide with $M_{\mathrm{n}}=1700 \mathrm{~g} / \mathrm{mol}$ (Elastamine HT-1700 or also known as XTJ-548) was supplied by Huntsman Corporation and used as received. Additional 1,5diamino-2-methylpentane/Dytek-A (99\%) was purchased from SigmaAldrich and used as received. Dimethylformamide (DMF) was purchased from Fisher Scientific and used as received. Divinylbenzene dicyclocarbonate (DVBDCC) was synthesized as described in ref. 53.

\subsection{Synthesis of PHUs}

All PHUs were synthesized according to Scheme 1. The naming convention for PHUs in this study is soft segment-XX, where the soft segment can be PBN18, PBN10, or PTMO and XX denotes the hard-segment content in the material. The hard-segment content is defined by [(weight of DVBDCC + weight of chain extender $) /($ weight of DVBDCC + weight of chain extender + weight of soft segment)] x $100 \%$. In a typical synthesis of PBN18-30, $3.0 \mathrm{~g}$ of PBN18 (comprised of $0.70 \mathrm{mmol}$ of Dytek-A-terminated polybutadiene-co-acrylonitrile oligomers and $2.81 \mathrm{mmol}$ Dytek-A), and $0.88 \mathrm{~g}(3.51 \mathrm{mmol})$ of DVBDCC were combined into a Max20 cup (FlackTek ${ }^{\mathrm{TM}}$ ). Then, $2.0 \mathrm{~mL}$ of DMF were added to solubilize the mixture and to bring the concentration of reacting groups to $\sim 0.50 \mathrm{M}$. The mixture was homogenized in a FlackTek SpeedMixer ${ }^{\mathrm{TM}}$ for $1.0 \mathrm{~min}$ and transferred to a $20-\mathrm{mL}$ vial where it reacted at $80{ }^{\circ} \mathrm{C}$ for $24 \mathrm{~h}$ with stirring. In a typical synthesis of PBN10-30, $3.0 \mathrm{~g}$ of PBN10 (comprised of $0.70 \mathrm{mmol}$ 
of Dytek-A-terminated polybutadiene-co-acrylonitrile oligomers and $1.66 \mathrm{mmol}$ of DYTEK-A), $0.88 \mathrm{~g}(3.51 \mathrm{mmol})$ of DVBDCC and $0.13 \mathrm{~g}(1.14 \mathrm{mmol})$ of Dytek-A were combined into a Max20 cup. Then, $2.3 \mathrm{~mL}$ of DMF were added to solubilize the mixture and to bring the concentration of reacting groups to $\sim 0.50 \mathrm{M}$. The mixture was homogenized in a FlackTek SpeedMixer ${ }^{\mathrm{TM}}$ for $1.0 \mathrm{~min}$ and transferred to a 20 - $\mathrm{mL}$ vial and let to react at $80{ }^{\circ} \mathrm{C}$ for $24 \mathrm{~h}$ with stirring. In a typical synthesis of PTMO-30, $1.5 \mathrm{~g}(6.0 \mathrm{mmol})$ of DVBDCC, $4.37 \mathrm{~g}(2.77 \mathrm{mmol})$ of Elastamine HT-1700, $0.382 \mathrm{~g} \mathrm{(3.22} \mathrm{mmol} \mathrm{of} \mathrm{Dytek-A)} \mathrm{and} 3.7 \mathrm{~mL}$ of DMF were combined into a Max20 cup and homogenized. The mixture was transferred to a $20-\mathrm{mL}$ vial where it reacted at $80^{\circ} \mathrm{C}$ for $24 \mathrm{~h}$ with stirring.
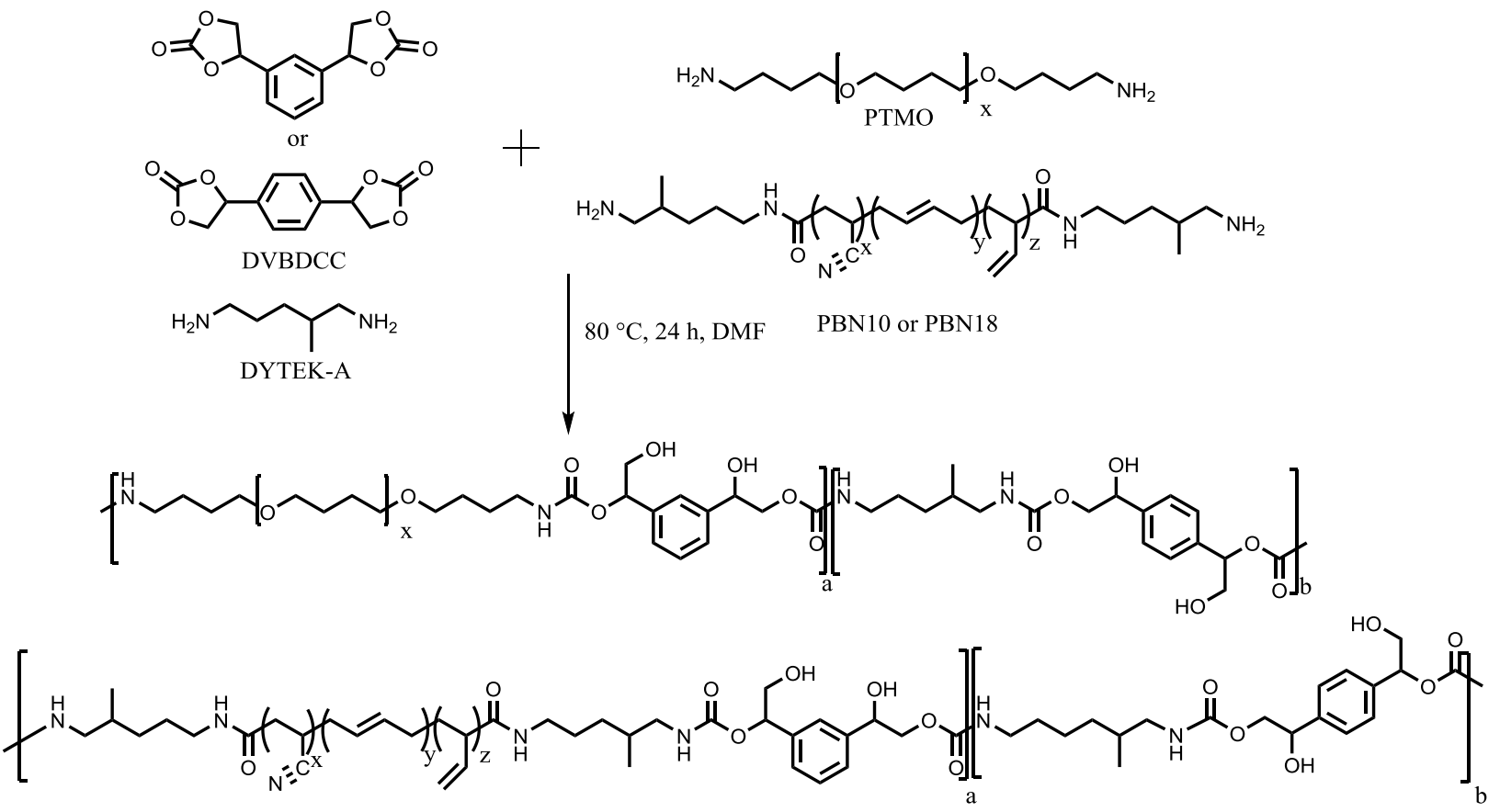

DVBDCC
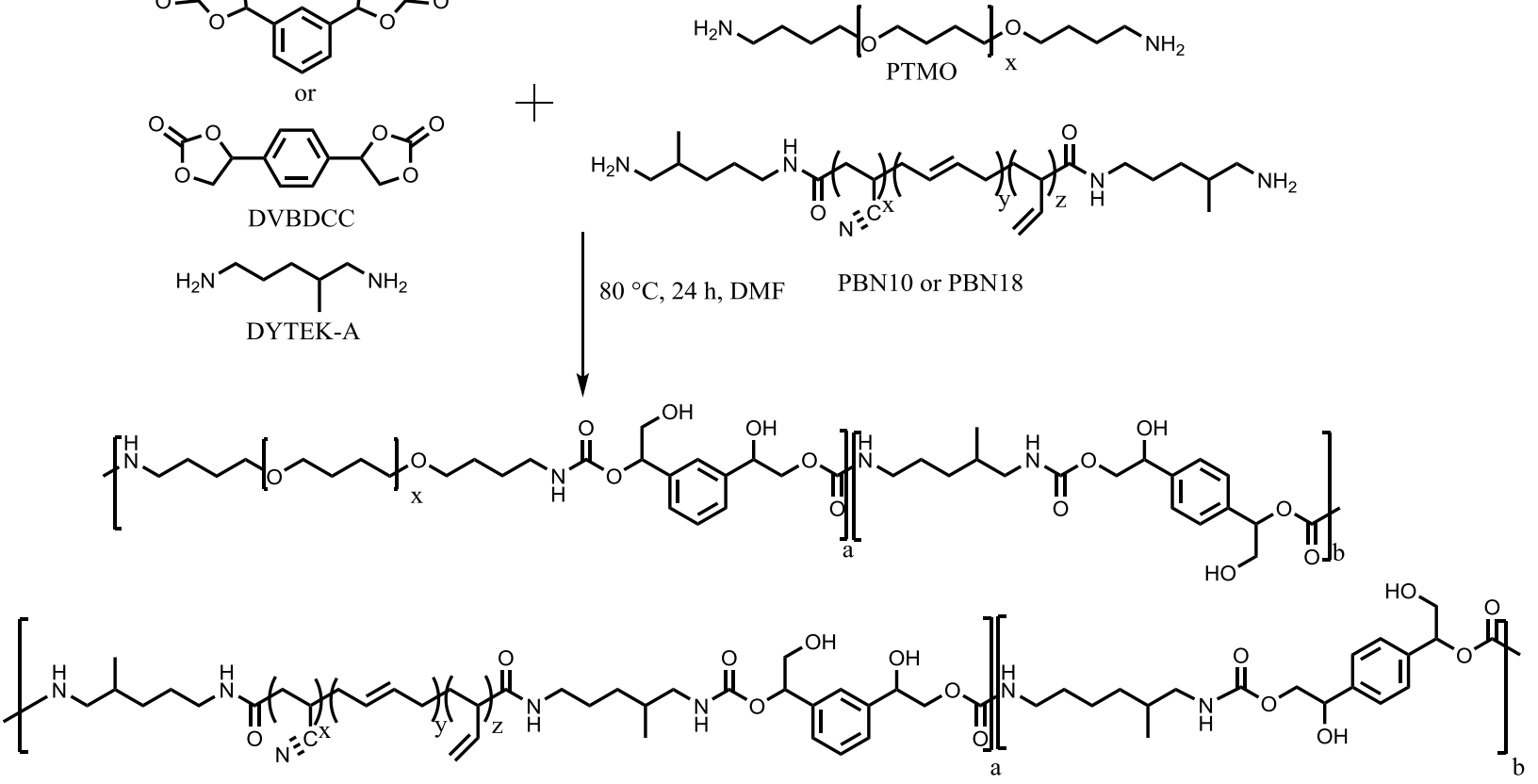

Scheme 1. Reaction schemes for synthesis of PTMO-based and PBN-based PHUs.

\subsection{Characterization of PHUs}

Attenuated total reflectance-Fourier transform infrared (ATR-FTIR) spectroscopy was performed with a Bruker Tensor 37 MiD IR FTIR spectrophotometer equipped with a diamond/ZnSe attachment. All PHUs were scanned at a resolution of $4 \mathrm{~cm}^{-1}$ and 32 scans were collected in the 4000-600 $\mathrm{cm}^{-1}$ range. The conversion of the starting materials were determined by analyzing carbonate carbonyl groups of DVBDCC at $\sim 1800 \mathrm{~cm}^{-1}$. The urethane carbonyl 
peaks located at $\sim 1730-1700 \mathrm{~cm}^{-1}$ were analyzed to determine the extent of hydrogen bonding in the urethane carbonyl regions. ${ }^{1} \mathrm{H}$ NMR spectra were recorded on a Bruker Avance III $500 \mathrm{MHz}$ NMR spectrometer with a direct cryoprobe at room temperature in deuterated chloroform $\left(\mathrm{CDCl}_{3}\right)$. Spectra were reported in parts per million relative to tetramethylsilane. The molecular weights (MWs) of PHUs were determined using gel permeation chromatography (GPC). A Waters 2695 separation module and two Tosoh TSKgel Alpha-M columns (particle size13 $\mu \mathrm{m}$, mixed-bed, $30 \mathrm{~cm}$ long, P/N 0018334) in series were used with $4 \mathrm{~cm}$ guard column (TSK guardcolumn alpha, P/N 0018345. The eluent was DMF with $4.0 \mathrm{~g} / \mathrm{L}$ of $\mathrm{LiNO}_{3}$ at $40{ }^{\circ} \mathrm{C}$; the elution rate was $0.5 \mathrm{~mL} / \mathrm{min}$. The detector was a Viscotek TDA 302 interface/Waters $2414 \mathrm{RI}$ detector. Molecular weight values were reported relative to polyethylene oxide (PEO) standards. Agilent PEO/PEG EasiCal P/N 2080-0201/0202 was used for calibration.

SAXS experiments were performed using a Rigaku S-MAX 3000 SAXS system emitting X-rays with a wavelength of $0.154 \mathrm{~nm}(\mathrm{Cu}-\mathrm{K} \alpha)$. The sample-to-detector distance was $1640 \mathrm{~mm}$ with silver behenate calibration. The $2 \mathrm{D}$ scattering patterns were azimuthally averaged to produce 1 -D plots of intensity versus scattering vector $q$, where $q=4 \pi \sin \theta / \lambda$; $\theta$ is one-half of the scattering angle, and $\lambda$ is the $\mathrm{X}$-ray wavelength.

AFM samples were prepared by drop casting $10 \mathrm{wt} \%$ solutions of PHU in DMF onto glass cover slides. Samples were dried for $24 \mathrm{~h}$ at $80{ }^{\circ} \mathrm{C}$. AFM phase imaging was performed using a Bruker Dimension FastScan Atomic Force Microscope in tapping mode.

DMA experiments were performed with a TA Instruments Rheometrics Stress AnalyzerGIII. Rectangular specimens measuring $8.0 \mathrm{~mm}$ in width and $0.9 \mathrm{~mm}$ in thickness were cooled with $\mathrm{N}_{2}$ gas to $-100{ }^{\circ} \mathrm{C}$ and subjected to a temperature sweep from $-100{ }^{\circ} \mathrm{C}$ to $120{ }^{\circ} \mathrm{C}$ at a heating rate of $3{ }^{\circ} \mathrm{C} / \mathrm{min}$. The measurements were conducted in tensile mode at a frequency of $1 \mathrm{~Hz}$ and a strain of $0.03 \%$. The storage modulus $\left(E^{\prime}\right)$, loss modulus $\left(E^{\prime \prime}\right)$ and loss tangent $(\tan \delta)$ were recorded. The soft-segment $T_{\mathrm{g}}$ was identified from the peak maximum in $E$ "; the flow temperature was defined as the onset of inconsistent $\tan \delta$ data, close to the temperature at which the sample was no longer mechanically robust. Differential scanning calorimetry was performed 
using a Mettler Toledo DSC 822e. Samples were heated to a $100{ }^{\circ} \mathrm{C}$ and annealed for 5 min and subsequently quenched to $-80{ }^{\circ} \mathrm{C}$ and heated a second time at $10{ }^{\circ} \mathrm{C} / \mathrm{min}$, with $T_{\mathrm{g}}$ values determined upon second heat via the onset method.

Tensile properties were obtained according to ASTM D1708 standard with an MTS Sintech 20/G tensile tester. Dog bone-shaped samples $(4.7 \mathrm{~mm}$ x $1.0 \mathrm{~mm}$ x $22 \mathrm{~mm}$ ) were cut using a Dewes-Gumbs die from dried sheets and subjected to an extension rate of $130 \mathrm{~mm} / \mathrm{min}$. The Young's modulus, tensile strength and elongation at break were reported as average values of five specimens. Error represents one standard deviation.

\section{RESULTS AND DISCUSSION}

\subsection{Synthesis and Characterization of PHU Molecular Structure}

All PHUs were synthesized according to Scheme 1. The successful synthesis of PHU was confirmed by FTIR and NMR spectroscopy. Figure S1 shows FTIR spectra of all polymers along with the spectrum of the DVBDCC starting material. The carbonate peak at $\sim 1800 \mathrm{~cm}^{-1}$ present in the DVBDCC sample is absent in all PHU samples, indicating complete conversion of carbonate functional groups into hydroxyurethane linkages within experimental error. The urethane carbonyl stretch (1730-1700 $\left.\mathrm{cm}^{-1}\right)$, amide stretch $\left(3500-3300 \mathrm{~cm}^{-1}\right)$, and hydroxyl stretch (3500-3100 $\left.\mathrm{cm}^{-1}\right)$ were present in the spectra of these PHUs. The nitrile stretch $(\sim 2238$

$\left.\mathrm{cm}^{-1}\right)$ and ether $\left(\sim 1100 \mathrm{~cm}^{-1}\right)$ groups were present in PBN- and PTMO-based PHUs, respectively, indicating successful incorporation of soft-segment molecules into the polymer. The successful formation of PHUs was also confirmed by ${ }^{1} \mathrm{H}$ NMR spectroscopy. Figures S2-S7 show NMR spectra of all PHUs, with positions of various protons within the polymer assigned accordingly.

Apparent molecular weight (MW) averages of these PHUs were determined by GPC and are tabulated in Table S1; all apparent MW averages are relatively low. The achievement of relatively low MW during synthesis of PHUs was also reported in a recent study by Averous and coworkers [82] who synthesized segmented PHUs using fatty-acid based diamine, terephthaloyl bis-carbonate and diamine-terminated polypropylene glycol (Jeffamine ${ }^{\mathrm{TM}}$ D2000); other studies 
have made related reports $[44,45,53,54,83,84]$. A recent study on segmented, PTMO-based PHU by Long and coworkers [55] also noted that the MWs of their PHUs might be low although no data were provided. Additionally, we consider it possible that PHUs undergo some GPC column interaction. Long and coworkers noted that column interaction was observed in their system, even for PHU with the lowest hard-segment content (with the lowest amount of hydroxyurethane and amide linkages) [55]. Future study is needed to produce higher MW PHU, possibly by using more reactive six- or eight-membered-ring carbonates or via the aid of organic catalysts [29,30].

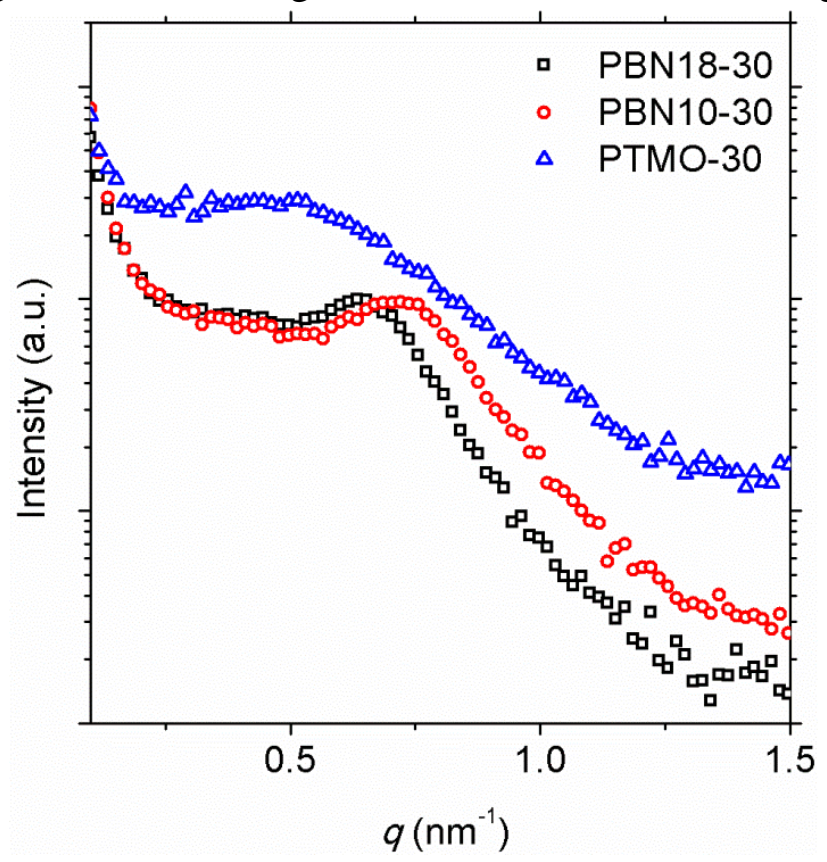

Figure 1. Small-angle X-ray scattering patterns of PTMO-30, PBN18-30 and PBN10-30.

\subsection{SAXS}

The hard and soft segments in segmented PUs are thermodynamically incompatible resulting in segregation of hard segments into nanosized-domains dispersed within a rubbery matrix. The hydrogen bonding between the urethane units and the vitrification of the hard domains reinforce the nanophase-separated structures in segmented PUs. SAXS is commonly used to probe the existence, degree and kinetics of nanophase separation in PU [85-88]. The SAXS patterns of PBN-based and PTMO-based PHUs are shown in Figure 1. Nanophase separation is evident from the peak in scattered intensity for each PHU. The interdomain spacing 
(d) can be determined from the peak location in scattered intensity. For all PHUs, $d$ values are 9-16 nm (see Table 1), with the $40 \mathrm{wt} \%$ hard-segment content PHUs exhibiting larger $d$ values than their $30 \mathrm{wt} \%$ analogues, consistent with larger hard-segment domains being present at higher hard-segment content. At equal hard-segment content, PTMO-based PHUs have larger $d$ values than the PBN-based PHUs even though the PTMO-based soft segment is of lower MW than those of the PBN-based soft segments. The origin for this difference as a function of softsegment species warrants further study.

Table 1. Summary of interdomain spacing, thermal and mechanical properties of PTMO- and PBN-based PHUs

\begin{tabular}{c|c|c|c|c|c|c|c|c}
\hline Material & $\begin{array}{c}d \text {-spacing } \\
(\mathrm{nm})\end{array}$ & $\begin{array}{c}\mathrm{SS} T_{\mathrm{g}} \\
(\mathrm{DSC}) \\
\left({ }^{\circ} \mathrm{C}\right)^{\mathrm{a}}\end{array}$ & $\begin{array}{c}\mathrm{SS} T_{\mathrm{g}} \\
(\mathrm{DMA}) \\
\left({ }^{\circ} \mathrm{C}\right)\end{array}$ & $\begin{array}{c}\mathrm{HS} T_{\mathrm{g}} \\
(\mathrm{DSC}) \\
\left({ }^{\circ} \mathrm{C}\right){ }^{\mathrm{c}}\end{array}$ & $\begin{array}{c}T_{\text {flow }} \\
(\mathrm{DMA}) \\
\left({ }^{\circ} \mathrm{C}\right)\end{array}$ & $\begin{array}{c}\text { Young's } \\
\text { Modulus } \\
(\mathrm{MPa})\end{array}$ & $\begin{array}{c}\text { Tensile } \\
\text { Strength } \\
(\mathrm{MPa})\end{array}$ & $\begin{array}{c}\text { Elongation } \\
\text { at Break } \\
(\%)\end{array}$ \\
\hline PBN18-30 & 10.1 & -60 to -48 & -46 & 17 to 49 & 52 & $48 \pm 7$ & $1.1 \pm 0.2$ & $900 \pm 200$ \\
PBN18-40 & 13.4 & -60 to -48 & -48 & 35 to 50 & 65 & $53 \pm 5$ & $1.0 \pm 0.3$ & $300 \pm 130$ \\
PBN10-30 & 9.6 & -72 to -63 & -62 & 8 to 48 & 43 & $56 \pm 4$ & $0.6 \pm 0.1$ & $720 \pm 100$ \\
PBN10-40 & 10.7 & -74 to -64 & -57 & 38 to 58 & 73 & $61 \pm 4$ & $0.8 \pm 0.1$ & $100 \pm 60$ \\
PTMO-30 & 12.6 & - & -65 & - & 40 & $23 \pm 6$ & $0.4 \pm 0.1$ & $>2000$ \\
PTMO-40 & 16.1 & - & -65 & - & 40 & $36 \pm 3$ & $0.8 \pm 0.2$ & $1600 \pm 300$ \\
\hline
\end{tabular}

${ }^{\mathrm{a}}$ The onset and endset of the soft-segment $T_{\mathrm{g}} \mathrm{s}$ as determined by DSC using the first derivative method.

${ }^{\mathrm{b}}$ Determined from the peak in dynamic loss modulus $\left(E^{\prime \prime}\right)$ in DMA.

${ }^{\mathrm{c}}$ The onset and endset of the hard segment $T_{\mathrm{g}} \mathrm{s}$ as determined by DSC using the first derivative method.

${ }^{\mathrm{d}}$ Determined from the onset of inconsistent tan $\delta$ data using DMA, close to the temperature at which the sample is no longer mechanically robust.

\subsection{DMA}

The thermomechanical properties of PHUs synthesized in this study were analyzed using DMA. Consistent with the presence of nanophase-separated structures, all PHUs show two thermal transitions corresponding to $T_{\mathrm{g}} \mathrm{s}$ of the soft and hard segments. The soft-segment $T_{\mathrm{g}}$ is identified from the peak in loss modulus ( $\left.E^{\prime}\right)$ located well below ambient temperature. As determined by DMA, in PTMO-based PHUs the soft-segment $T_{\mathrm{g}} \mathrm{s}$ are $\sim-67{ }^{\circ} \mathrm{C}$ whereas in PBNbased PHUs the soft-segment $T_{\mathrm{g}} \mathrm{s}$ are $\sim-54$ and $\sim-67{ }^{\circ} \mathrm{C}$ for PBN18 and PBN10 soft segments, respectively. The $T_{\text {flow }}$ values, related to the hard-segment domain undergoing a transition from a glassy state to a liquid state upon heating, resulting in loss of any mechanical robustness, are above room temperature. Table 1 summarizes the thermal transition values obtained by DMA.

The general shapes of DMA profiles for PTMO-based and PBN-based PHUs differ 
significantly, testifying to the different nanophase separation behavior obtained as a function of soft-segment choice in segmented PHUs. Figure 2a shows the temperature dependences of $E^{\prime}, E^{\prime}$ and $\tan \delta$ of PTMO-30. The value of $\log E$, shows a very gradual decrease with temperature above the soft-segment $T_{\mathrm{g}}$. The tan $\delta$-temperature profile of PTMO-30 shows high values exceeding 0.30 over a temperature range of more than $70{ }^{\circ} \mathrm{C}$ in breadth. The profiles obtained with PTMO-based PHUs are consistent with nanophase-separated systems with broad interphases having a wide range of local composition; such materials may serve as highly effective, broad-temperature-range damping materials [58].

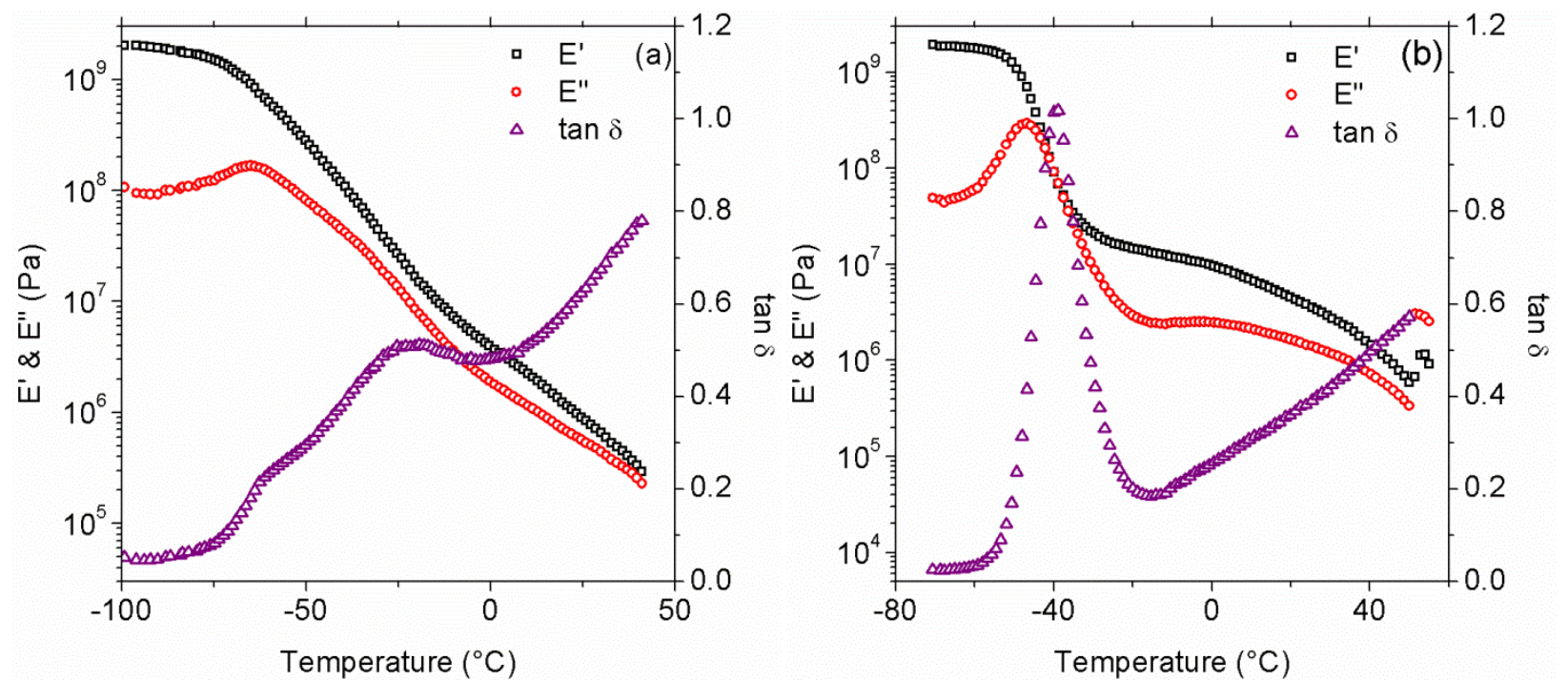

Figure 2. Temperature dependences of storage modulus $\left(E^{\prime}\right)$, loss modulus $\left(E^{\prime \prime}\right)$ and loss factor $(\tan \delta)$ of PHUs synthesized with a) PTMO soft segment, PTMO-30, and b) polybutadiene-co-acrylontrile, $18 \mathrm{wt} \%$ acrylonitrile soft segment, PBN18-30.

Figure $2 \mathrm{~b}$ shows the temperature dependences of $E^{\prime}, E^{\prime \prime}$ and tan $\delta$ of a typical PBN-based PHU, PBN18-30. In contrast to PTMO-30, PBN18-30 manifests two distinct, roughly stepwise transitions in its $\log E^{\prime}$-temperature curve with sharp, well-defined peaks in the $\tan \delta$ temperature curve. The first drop in $\log E^{\prime}$ upon heating near the soft-segment $T_{\mathrm{g}}$ is followed by a rubbery plateau region which extends several tens of degrees prior to another drop in $\log E$, due to the hard segment undergoing a transition from a glassy state to a liquid state. This profile is consistent with the behavior of a nanophase-separated system with sharp domain interphases such as those observed in conventional segmented PUs or conventional, nanostructured block 
copolymers. The difference in nanophase separation behavior in these PHUs is a direct result of hydrogen bonding. In PTMO-based PHUs, the hard-segment hydroxyl groups can undergo hydrogen bonding with oxygen atoms in the soft segment, causing some level of phase mixing $[53,54]$. This intersegmental hydrogen bonding then leads to interphase regions with a wide range of local composition. The switch to a PBN-based soft segment eliminates intersegmental hydrogen bonding and leads to improved nanophase separation and sharper domain interphases.

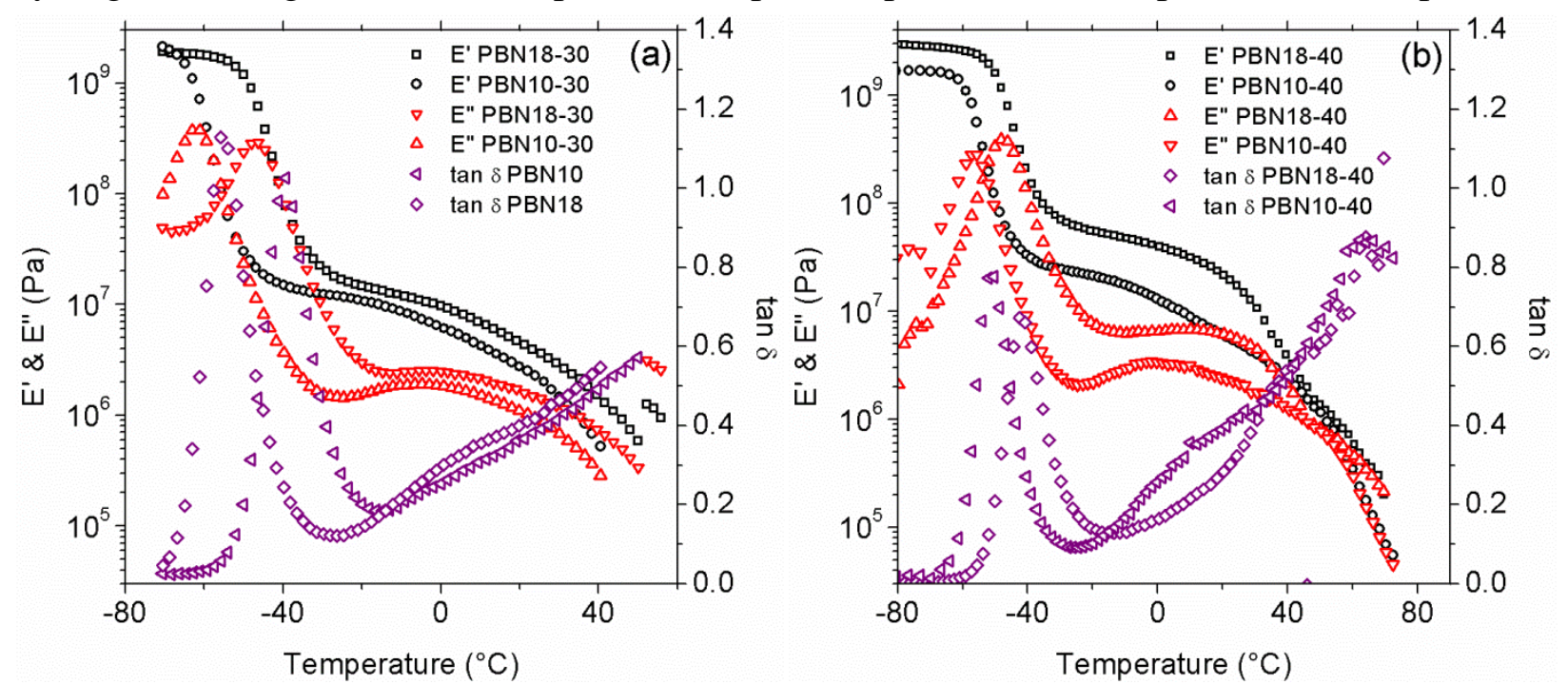

Figure 3. Temperature dependences of storage modulus $\left(E^{\prime}\right)$, loss modulus $\left(E^{\prime \prime}\right)$ and loss factor $(\tan \delta)$ of PHUs synthesized with polybutadiene-co-acrylonitrile soft segments at a) $30 \mathrm{wt} \%$ hard-segment content (PBN18-30 and PBN10-30) and b) $40 \mathrm{wt} \%$ hard-segment content (PBN18-40 and PBN10-40).

Figure 3 shows the temperature dependences of $E^{\prime}, E^{\prime}$ and tan $\delta$ for PHUs synthesized with PBN18 and PBN10 at $30 \mathrm{wt} \%$ and $40 \mathrm{wt} \%$ hard-segment contents. Despite the difference in acrylonitrile content in the soft segments, both PHUs show similar thermomechanical responses, with only the values of the soft-segment $T_{\mathrm{g}} \mathrm{s}$ changing significantly as a function of acrylonitrile content in the soft segment. Thus, for the PBN-based soft segments employed here, the softsegment acrylonitrile content has little influence on the nanophase separation behavior.

Figure 3 also reveals that the rubbery plateau modulus and $T_{\text {flow }}$ value increase with increasing hard-segment content. In PBN18-based PHUs, $T_{\text {flow }}$ increases from 52 to $65{ }^{\circ} \mathrm{C}$ as hard-segment content increases from $30 \mathrm{wt} \%$ to $40 \mathrm{wt} \%$. This effect can be attributed to increased physical crosslinking with increasing hard-segment content and a more perfected hard- 
segment domain. This interpretation is also supported by the fact that the interdomain spacing from SAXS measurements increases from 10.1 to $13.4 \mathrm{~nm}$ with increasing hard-segment content in PBN18-based PHUs. This means that the size of the hard segment nanodomains are smaller in the $30 \mathrm{wt} \%$ hard-segment PHU, likely $<5 \mathrm{~nm}$ in diameter, leading to more imperfect phase separation and thus a lower hard-segment domain $T_{\mathrm{g}}$.

As shown in Figure 3, the slope of the $\log E$ ' vs. temperature curve in the "rubbery plateau" regime provides a qualitative measure of the degree and perfection of nanophase separation in segmented PUs. In some well phase-separated PU systems $[63,65,76,80,81]$, the rubbery plateau regime is almost unchanging with temperature, i.e., the slope is nearly zero or only slightly negative. The slopes of the "rubbery plateau" regions in the PBN-based PHUs considered here are more temperature-sensitive, possibly because some mixing of hard and soft segments still persists. Nevertheless, the nanophase separation is much sharper in PHUs with PBN-based soft segments relative to PHUs with PTMO-based soft segments. The dramatic difference observed in DMA results between PTMO-based PHUs and PBN-based PHUs demonstrates that nanophase separation behavior can be tuned significantly in segmented PHU by judicious choice of soft segment.

It is worth noting that the presence of acrylonitrile in the soft-segment of PBN-based PHUs does not result in extensive phase mixing. Previous studies have shown that nitrile groups are capable of forming hydrogen bonds with hydroxyl groups [89-91]. However, we observed that nanophase-separated PBN-based PHUs exhibit behavior consistent with sharper interphase regions than those of PTMO-based PHUs, which indicates that the acrylonitrile units are not interacting significantly with hydroxyl groups in the hard segment to cause phase mixing. We hypothesize that this behavior arises from acrylonitrile units that are self-associating in the soft domain instead of participating in hydrogen bonding with hydroxyl groups. Self-association of acrylonitrile units due to a strong dipole-dipole interaction is well studied in the literature [9294]. This self-association is also supported by the location of nitrile peaks of PBN-based PHUs from FTIR measurement (see Figure S8). The nitrile peaks in PBN-based PHUs appear at 2238 
$\mathrm{cm}^{-1}$, equivalent to acrylonitrile groups in bulk polyacrylonitrile. Studies by Lachat et al. [91] indicated that high temperature and pressure are needed to break nitrile-nitrile interactions and replace them with nitrile-hydroxyl interactions. In other words, under the conditions of our study, nitrile-hydroxyl interactions are insufficiently strong to disrupt nitrile-nitrile interactions. As a result of acrylonitrile self-association, the soft segment is reinforced and the hard segment is effectively excluded from the soft segment leading to better nanophase separation. We note that a study by Maglio and coworkers on PBN-based segmented PUs also indicated that there is no extensive phase mixing of soft and hard segments based on DSC and DMA characterization [76].
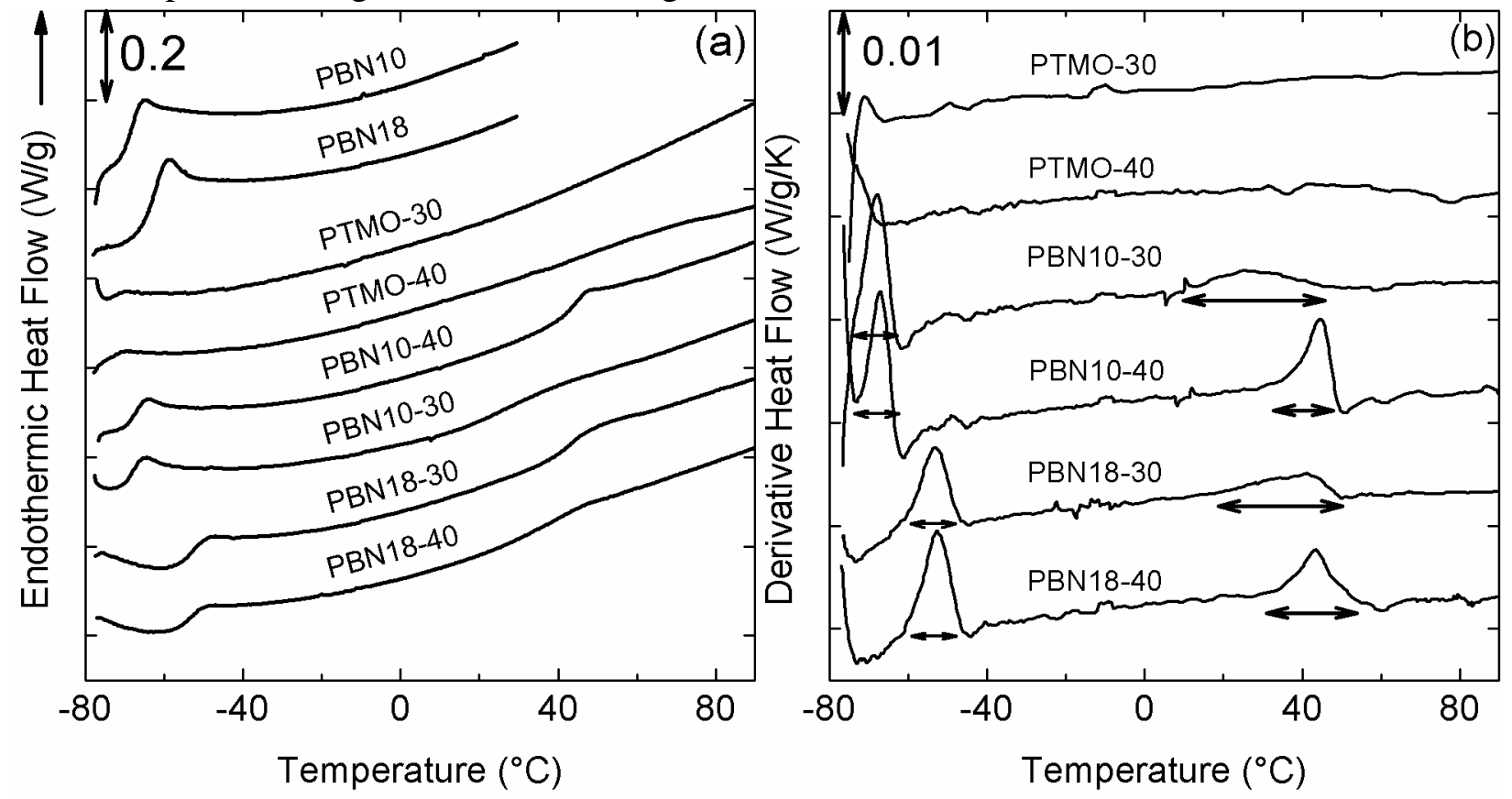

Figure 4. Thermal properties of PHUs as characterized by DSC. a) Representative heat flow curves of PHUs at a heating rate of $10^{\circ} \mathrm{C} / \mathrm{min}$ and, b) first derivative heat flow curves of PHUs.

\section{$3.4 D S C$}

Figure 4a shows DSC heat flow curves of all PHUs. The PTMO-based PHUs do not exhibit distinct hard-segment thermal transitions, likely due, at least in part, to their broad interphases leading to very broad and hence weak $T_{\mathrm{g}}$ responses. The hard-segment hydroxyl groups can hydrogen bond with soft-segment ether oxygen atoms resulting in some level of phase mixing, thus making thermal transitions in PTMO-based PHUs difficult to discern by DSC [54]. In contrast, two distinct thermal transitions below and above ambient temperature 
corresponding to the soft- and hard-segment $T_{\mathrm{g}} \mathrm{s}$ are clearly observed in all PBN-based PHUs. The distinct thermal transitions observed by DSC in PBN-based PHUs indicate that PBN-based soft segments result in better nanophase separation and sharper domain interphases than PTMObased soft segments and consequently more discernible thermal transitions of each domain.

To quantify further the transition breadths in these PHUs, we plot the first derivative heat flow curves in Figure $4 \mathrm{~b}$. First derivative heat flow curves have been useful in determining the glass transition responses of minor phases in materials or when there is only a small change in heat capacity. Derivative heat flow curves also permit quantification of $T_{\mathrm{g}}$ breadth which is related to compositional heterogeneity or phase mixing [95-97]. The first derivative heat flow curves of PTMO-based PHUs do not show any discernible features, indicating that the thermal transition(s) in PTMO-based PHUs, easily apparent via DMA, are not be amenable to DSC characterization.

The derivative heat flow curves of PBN-based PHUs provide further information on thermal transition breadths in PBN-based PHUs. As shown in Figure 4b, the apparent softsegment glass transition breadths for PBN18-30 and PBN10-30 span the ranges from -60 to -48 ${ }^{\circ} \mathrm{C}$ and -72 to $-63{ }^{\circ} \mathrm{C}$, respectively. These values are elevated only by $\sim 10{ }^{\circ} \mathrm{C}$ from the $T_{\mathrm{g}} \mathrm{s}$ of the corresponding pure soft-segment homopolymers, consistent with a high degree of nanophase separation in PBN-based PHUs. Increasing the hard-segment content to $40 \mathrm{wt} \%$ in the cases of PBN18-40 and PBN10-40 does not significantly alter the soft-segment domain $T_{\mathrm{g}} \mathrm{s}$. The proximity of the soft-segment domain $T_{\mathrm{g}}$ values to the $T_{\mathrm{g}}$ of its corresponding homopolymer and their invariance with respect to the hard-segment content indicate a high level of nanophase separation in PBN-based PHUs. These results agree with DSC characterization of several polybutadiene-based segmented PUs reported by Schneider and coworkers [67-70] as well as our DMA results on the same PBN-based PHUs.

Figure $4 \mathrm{~b}$ also shows that PBN-based PHUs exhibit broader hard-segment $T_{\mathrm{g}}$ regions as hard-segment decreases from 40 to $30 \mathrm{wt} \%$. The hard-segment glass transition regions for PBN18-40 and PBN10-40 span 35 to $50{ }^{\circ} \mathrm{C}$ and 38 to $58{ }^{\circ} \mathrm{C}$, respectively, whereas those for 
PBN18-30 and PBN10-30 span 17 to $49{ }^{\circ} \mathrm{C}$ and 8 to $48{ }^{\circ} \mathrm{C}$, respectively. The endset $T_{\mathrm{g}}$ reported by DSC is lower than $T_{\text {flow }}$ by DMA, in accord with literature reports [98-101]. As described above regarding DMA results, the effect of decreasing hard-segment content on glass transition breadth can be attributed at least in part to the decrease in size of hard-segment nanodomains, which likely leads to less perfect nanophase separation and thus a broader glass transition.

\subsection{AFM}

Surface morphological characterization of segmented PUs by AFM has been used to provide supporting evidence of nanophase separation [62-65]. Imaging of phase segregation in PTMO-based PHUs was met with limited success. The limitations may be caused by the low contrast between domains in PTMO-based PHUs as a result of their broad domain interphases. A similar limitation in imaging phase-segregated domains was previously reported in gradient copolymer systems that possess broad interphases with a wide range of local composition [89]. AFM phase images from a recent study of PTMO-based segmented PHUs by Long and coworkers [55] provided relatively strong compositional contrasts between hard and soft domains. However, this response was likely caused by the ability of the hard segments to crystallize. Their polymers also possessed amide linkages and one-half the content of hydroxyl groups possessed by our PHUs. Long and coworkers also noted that there was significant phase mixing between domains in their PHUs as evidenced from DMA and DSC results [55].

Figure S9a-c compares AFM phase images of PBN18-40 and PBN10-40 with PTMO-30. For the PBN-based PHUs, the light regions correspond to hard domains and the dark regions to soft domains. Contrast between soft and hard domains is evident in PBN-based PHUs, but little or no contrast is evident in PTMO-based PHUs. These results are consistent with less effective nanophase separation and the presence of substantial phase mixing in the PTMO-based PHUs, in agreement with DMA and DSC characterization.

\subsection{FTIR}

The level of nanophase separation in segmented PUs can be inferred from the strength of hydrogen bonding interactions in the hard segment. FTIR is commonly used to evaluate the 
degree and kinetics of nanophase separation by comparison of spectral bands associated with urethane carbonyl groups and amide groups [103-111]. The carbonyl region may display two characteristics: one associated with free, non-hydrogen-bonded carbonyl presenting as a shoulder centered at $\sim 1730 \mathrm{~cm}^{-1}$ and a second associated with hydrogen-bonded carbonyl presenting as a peak centered at $\sim 1700 \mathrm{~cm}^{-1}$. Figure 5 shows FTIR spectra in the carbonyl regions of all PHUs. Based on Figure 5, the PTMO-based PHUs exhibit the presence of both free, non-hydrogen bonded carbonyl and hydrogen bonded carbonyl; in contrast, the PBN-based PHUs exhibit no evidence of a shoulder at $\sim 1730 \mathrm{~cm}^{-1}$, consistent with well-hydrogen-bonded carbonyl. These results indicate that the lack of ether oxygen atoms as hydrogen bond acceptors in PBN-based soft segment limits hydrogen bonding to occur within the hard segment of PBN-based PHUs and thus nanophase separation to occur without substantial phase mixing. In contrast, in PTMObased PHUs, the hard-segment hydroxyl groups can form hydrogen bonds with soft segment oxygen atoms giving rise to a distribution of free and hydrogen-bonded carbonyls.

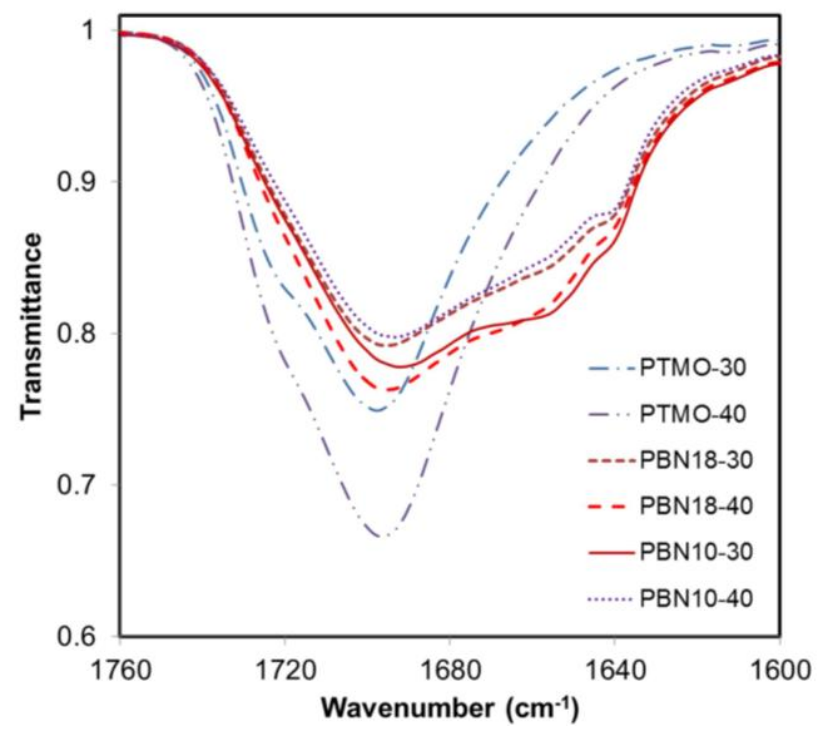

Figure 5. FTIR spectra of the carbonyl regions representing free, non-hydrogen bonded urethane carbonyl $(\sim 1730$ $\left.\mathrm{cm}^{-1}\right)$ and hydrogen bonded urethane carbonyl $\left(\sim 1700 \mathrm{~cm}^{-1}\right)$. PBN-based PHUs show peaks centered at $\sim 1670$ and $1640 \mathrm{~cm}^{-1}$, associated with free and hydrogen bonded amide carbonyl in the soft segment.

The FTIR spectra of PBN-based PHUs also show carbonyl absorbance at $\sim 1670$ and $\sim 1640 \mathrm{~cm}^{-1}$. These bands are attributed to free and hydrogen-bonded amide groups which are located at the terminal units of PBN18 and PBN10 soft segments incorporated in the PHUs [112- 
114]. Although the amide groups may participate in hydrogen bonding, we doubt that these amide groups contribute significantly to the apparent improvement in nanophase separation observed in PBN-based PHUs because they are present at much lower concentration than the hydroxyl groups. Future study is warranted to investigate the influence of such amide groups on nanophase separation.

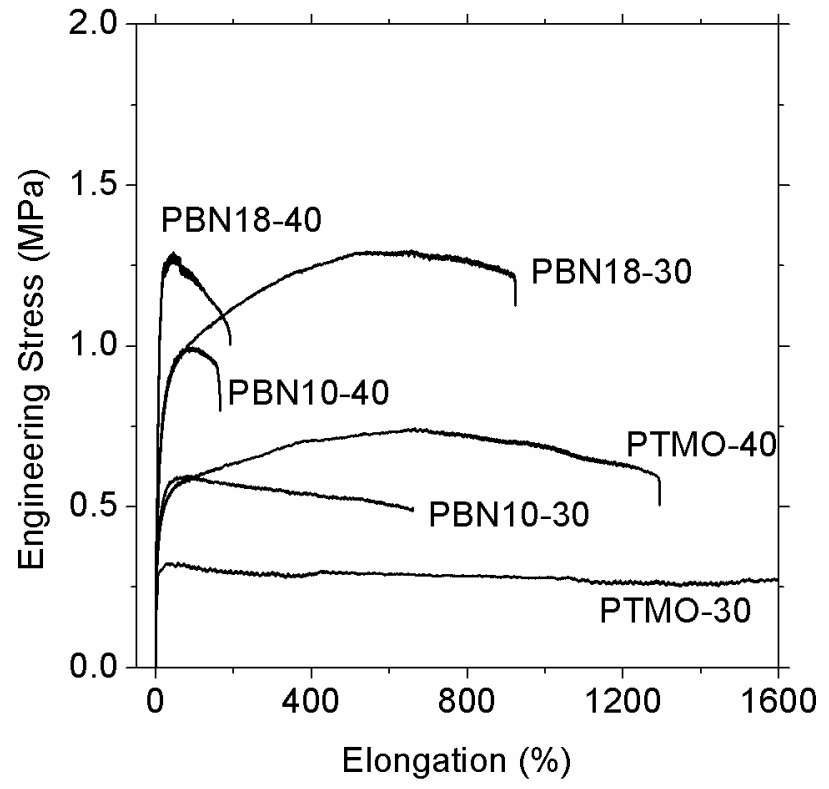

Figure 6. Representative stress-strain curves of PHUs characterized by uniaxial tensile testing.

\subsection{Tensile Testing}

Figure 6 displays representative stress-strain curves of all PHUs during tensile deformation. Table 1 lists average values of Young's modulus, ultimate tensile strength, and elongation at break. The PTMO-based PHUs exhibit tensile strengths up to $0.8 \mathrm{MPa}$ whereas PBN-based PHUs exhibit tensile strengths up to 1.1 MPa. Relative to PTMO-based PHUs, the PBN-based PHUs experience a larger reduction in elongation-at-break values with increasing hard-segment content. This result is in agreement with previous studies of segmented PUs with nonpolar soft segments such as polyisobutylene and polybutadiene, which show large reductions in elongation-at-break values with increasing hard-segment content [67,69,115-117]. Segmented PUs with nonpolar soft segments typically possess a very sharp domain interphase $[73,115,116]$. Cooper and coworkers suggested that poor interfacial adhesion between the hard and soft 
segments and localization of shear stress in the hard segment might lead to lower elongation-atbreak values with higher hard-segment content in PUs made with nonpolar soft segment [117]. This explanation is in accord with results from our study showing that PBN-based PHUs possess a much sharper domain interphase relative to PTMO-based PHUs.

In general, elongation-at-break and Young's modulus values of the PHUs in this study are similar to those obtained in conventional TPUs; however, the tensile strength values of the PHUs are inferior [66-69]. Further structure-property-relationship studies which consider the influences of hard-segment, chain-extender, and other soft-segment structures are warranted to obtain segmented PHUs with improved properties. Such studies are underway in our laboratory.

\section{CONCLUSION}

Tunability of nanophase separation behavior in segmented PHU was demonstrated via a simple change in soft-segment type. A series of PHUs were synthesized with PTMO- and PBNbased soft segments and characterized via SAXS, DMA, DSC, AFM, FTIR spectroscopy and tensile testing. SAXS results demonstrate the presence of nanophase-separated structures in all PHUs with 9-16 nm interdomain spacings of the hard-segment domains. DMA characterization shows that PTMO-based PHUs exhibit nanophase separation with broad interphases having a wide range of local composition. The broad interphases are a result of small to moderate levels of phase mixing originating from hard-segment hydroxyl groups undergoing hydrogen bonding with ether oxygen in the PTMO backbone. A change to PBN-based soft segments results in PHUs having sharper domain interphases due to a lack of hydrogen bonding between hard and soft segments. These interpretations are supported by FTIR spectroscopy which indicates that a substantial proportion of non-hydrogen-bonded carbonyl is present in PTMO-based PHUs but absent in PBN-based PHUs. The polar acrylonitrile units in PBN have no significant impact on the nanophase separation, likely due to their self-association. DSC and AFM results provide further support of the significantly different nanophase separation in PTMO- and PBN-based PHUs. PHUs exhibited elongation-at-break and Young's modulus values generally in accord 
with conventional TPUs. However, tensile strengths were inferior to conventional TPUs, with values ranging from 0.6 to $1.1 \mathrm{MPa}$ and PBN-based PHUs being better than PTMO-based PHUs.

\section{ACKNOWLEDGEMENT}

This work was supported by the University Partnership Initiative between Northwestern University and The Dow Chemical Company. This work made use of central facilities supported by the MRSEC program of the National Science Foundation (DMR-1121262) at the Northwestern University Materials Research Science and Engineering Center as well as facilities supported by Northwestern University at the Integrated Molecular Structure Education and Research Center. The authors would like to thank Mr. Jeremy Pasatta from Emerald Performance Materials for supplying polybutadiene-co-acrylonitrile soft segments.

\section{REFERENCES:}

[1] B. Nohra, L. Candy, J.-F. Blanco, C. Guerin, Y. Raoul, Z. Mouloungui, Macromolecules 46 (2013) 3771-3792.

[2] Oertel, G., Polyurethane Handbook. 2nd ed.; Hanser Gardner, 1994.

[3] E. Delebecq, J.-P. Pascault, B. Boutevin, F. Ganachaud, Chem. Rev. 113 (2013) 80-118.

[4] H.-W. Engels, H.-G. Pirkl, R. Albers, R. W. Albach, J. Krause, A. Hoffmann, H. Casselmann, J. Dormish, Angew. Chem. Int. Ed. 52 (2013) 9422-9441.

[5] Comission Regulation (EC); Official Journal of European Union 2009, N552/2009.

[6] Methylene Diphenyl Isocyanate (MDI) and Related Compounds Action Plan, Toluene Diisocyanate (TDI) Action Plan, U.S Environmental Protection Agency: 2011. EPA news release, www.epa.gov, accessed on November 21, 2015.

[7] EPA Proposes Rule to Protect Customers from Harmful Chemicals Found in Homes and Schools, U.S. Environmental Protection Agency: 2015. EPA news release, www.epa.gov accessed on December 04, 2012 
[8] J. Guan, Y. Song, Y. Lin, X. Yin, M. Zuo, Y. Zhao, X. Tao, Q. Zheng, Ind. Eng. Chem. Res. 50 (2011) 6517-6527.

[9] M. S. Kathalewar, P. B. Joshi, A. S. Sabnis, V. C. Malshe, RSC Adv. 3 (2013) 41104129.

[10] H. Blattmann, M. Fleischer, M. Bähr, R. Mülhaupt, Macromol. Rapid Commun. 35 (2014) 1238-1254.

[11] L. Maissoneuve, O. Lamarzelle, E. Rix, E. Grau, H. Cramail, Chem. Rev. 115 (2015) 12407-12439.

[12] V. Besse, F. Camara, C. Voirin, R. Auvergne, S. Caillol, B. Boutevin, Polym. Chem. 4 (2013) 4545-4561.

[13] N. Kihara, T. Endo, J. Polym. Sci., Part A: Polym. Chem. 31 (1993) 2765-2773.

[14] A. Steblyanko, W. Choi, F. Sanda, T. Endo, J. Polym. Sci., Part A: Polym. Chem. 38 (2000) 2375-2380.

[15] B. Ochiai, S. Inoue, T. Endo, J. Polym. Sci., Part A: Polym. Chem. 43 (2005) 6613-6618.

[16] H. Tomita, F. Sanda, T. Endo, J. Polym. Sci., Part A: Polym. Chem. 38 (2001) 851-859.

[17] H. Tomita, F. Sanda, T. Endo, J. Polym. Sci., Part A: Polym. Chem. 39 (2001) 162-168.

[18] H. Tomita, F. Sanda, T. Endo, J. Polym. Sci., Part A: Polym. Chem. 39 (2001) 860-867.

[19] H. Tomita, F. Sanda, T. Endo, J. Polym. Sci., Part A: Polym. Chem. 39 (2001) 40914100.

[20] H. Tomita, F. Sanda, T. Endo, J. Polym. Sci., Part A: Polym. Chem. 39 (2001) 36783685.

[21] B. Ochiai, S. Inoue, T. Endo, J. Polym. Sci., Part A: Polym. Chem. 43 (2005) 6282-6286.

[22] B. Ochiai, Y. Satoh, T. Endo, Green Chem. 7 (2005) 765-767.

[23] M.-R. Kim, H.-S. Kim, C.-S. Ha, D.-W. Park, J.-K. Lee, J. Appl. Polym. Sci. 81 (2001) 2735-2743.

[24] O. L. Figovsky, L. D. Shapovalov, Macromol. Symp. 187 (2002) 325-332.

[25] O. Birukov, O. Figovsky, A. Leykin, R. Potashnikov, L. Shapovalov, Method of 
producing hybrid polyhydroxyurethane network on a base of carbonated-epoxidized unsaturated fatty acid triglycerides. U.S. Patent 20120208967, Aug 16, 2012.

[26] J. L. J. Van Velthoven, L. Gootjes, D. S. van Es, B. A. J. Noordover, J. Meuldijk, Eur Polym. J. 70 (2015) 125-135.

[27] C. Duval, N. Kébir, R. Jauseau, F. Burel, J Polym. Sci., Part A: Polym. Chem. 54 (2015) 758-764.

[28] M. Tryznowski, A. Świderska, Z. Żolek-Tryznowska, T. Gołofit, P. G. Parzuchowski, Polymer 80 (2015) 228-236.

[29] R. Lambeth, T. J. Henderson, Polymer 54 (2013) 5568-5573.

[30] V. M. Lombardo, E. A. Dhulst, E. K. Leitsch, N. Wilmot, W. H. Heath, A. P. Gies, M. D. Miller, J. M. Torkelson, K. A. Scheidt, Eur. J. Org. Chem. 13 (2015) 2791-2795.

[31] M. Blain, L. Jean-Gérard, R. Auvergne, D. Benazet, S. Caillol, B. Andrioletti, Green Chem. 16 (2014) 4286-4291.

[32] M. Bähr, R. Mülhaupt, Green Chem. 14 (2012) 483-489.

[33] B. Tamami, S. Sohn, G. L. Wilkes, J. Appl. Polym. Sci. 92 (2004) 883-891.

[34] I. Javni, D. P. Hong, Z. S. Petrović, J. Appl. Polym. Sci. 108 (2008) 3867-3875.

[35] I. Javni, D. P. Hong, Z. S. Petrović, J. Appl. Polym. Sci. 128 (2013) 566-571.

[36] M. Bähr, A. Bitto, R. Mülhaupt, Green Chem. 14 (2012) 1447-1454.

[37] M. Fleischer, H. Blattmann, R. Mülhaupt, Green Chem. 15 (2013) 934-942.

[38] V. Besse, R. Auvergne, S. Carlotti, G. Boutevin, B. Otazaghine, S. Caillol, J.-P. Pascault, B. Boutevin, React. Funct. Polym. 73 (2013) 588-594.

[39] M. Kathalewar, A. Sabnis, D. D’Mello, Eur. Polym. J. 57 (2014) 99-108

[40] A. Lee, Y. Deng, Eur. Polym. J. 63 (2015) 67-73.

[41] D. J. Fortman, J. P. Brutman, C. J. Cramer, M. A. Hillmyer, W. R. Dichtel, J. Am. Chem. Soc. 137 (2015) 14019-14022.

[42] H. Matsukizono, T. Endo, RSC Adv. 5 (2015) 71360-71369.

[43] A. Cornille, S. Dworakowska, D. Bogdal, B. Boutevin, S. Caillol, Eur. Polym. J. 66 
(2015) 129-138.

[44] S. Benyahya, M. Desroches, R. Auvergne, S. Carlotti, S. Caillol, B. Boutevin, Polym. Chem. 2 (2011) 2661-2667.

[45] S. Benyahya, J.-P. Habas, R. Auvergne, V. Lapinte, S. Caillol, Polym. Int. 61 (2012) 1666-1674.

[46] L. Maisonneuve, A. S. More, S. Foltran, C. Alfos, F. Robert, Y. Landais, T. Tassaing, E. Grau, H. Cramail, RSC Adv. 4 (2014) 25795-25803.

[47] C. N. Tang, H. B. Nulwala, K. Damodaran, P. Kaur, D. R. Luebke, J. Polym. Sci., Part A: Polym. Sci. 49 (2011) 2024-2032.

[48] T. Lebarbé, A. S. More, P. S. Sane, E. Grau, C. Alfos, H. Cramail, Macromol. Rapid Commun. 35 (2014) 479-483.

[49] X. Sheng, G. Ren, Y. Qin, X. Chen, X. Wang, F. Wang, Green Chem. 17 (2015) 373-379.

[50] L. Maisonneuve, A.-L. Wirotius, C. Alfos, E. Grau, H. Cramail, Polym. Chem. 5 (2014) 6142-6147.

[51] O. Lamarzelle, P.-L. Durand, A.-L. Wirotius, G. Chollet, E. Grau, H. Cramail, Polym. Chem. 7 (2016) 1439-1451.

[52] J. Nanclares, Z. S. Petrovic, I. Javni, M. Ionescu, F. Jaramillo, J. Appl. Polym. Sci. 132 (2015) 42492.

[53] E. K. Leitsch, G. Beniah, K. Liu, T. Lan, W. H. Heath, K. A. Scheidt, J. M. Torkelson, ACS Macro Lett. 5 (2016) 424-429.

[54] G. Beniah, K. Liu, W. H. Heath, K. A. Scheidt, M. D. Miller, J. M. Torkelson, Eur. Polym. J. 84 (2016) 770-783.

[55] K. Zhang; A. M. Nelson, S. J. Talley, M. Chen, E. Margaretta, A. G. Hudson, R. B. Moore, T. E. Long, Green Chem. 18 (2016) 4667-4681.

[56] W. Meckel, W. Goyert, W. Wieder, H.-G. Wussow, Thermoplastic Elastomers, 3rd Edition, Editors: G. Holden, H. R. Kricheldorf, E. P. Quirk, Hanser, Munich, 2004, 1543. 
[57] C. Hepburn, Polyurethane Elastomers, Chapter 3, Structure Property Relationship, Elsevier Science Publishers, 1992.

[58] M.M. Mok, J. Kim, and J.M. Torkelson, J. Polym. Sci., Part B: Polym. Phys. 46 (2008) 48-58.

[59] I. Yilgor, E. Yilgor, G. L. Wilkes, Polymer 58 (2015) A1-A36.

[60] T. Choi, J. Weksler, A. Padsalgikar, J. Runt, Polymer 50 (2009) 2320-2327.

[61] A. M. Castagna, A. Pangon, T. Choi, G. P. Dillon, J. Runt, Macromolecules 45 (2012) 8438-8444.

[62] D. B. Klinedinst, E. Yilgör, I. Yilgör, F. L. Beyer, G. L. Wilkes, Polymer 46 (2005) 10191-10201.

[63] S. P. Ertem, E. Yilgor, C. Kosak, G. L. Wilkes, M. Zhang, I. Yilgor, Polymer 53 (2012) 4614-4622.

[64] D. J. Martin, G. F. Meijs, P. A. Gunatillake, S. J. McCarthy, G. M. Renwick, J. Appl. Polym. Sci. 60 (1996) 557-571.

[65] L. T. J. Korley, B. D. Pate, E. L. Thomas, P. T. Hammond, Polymer 47 (2006) 30733082 .

[66] R. Zou, J. Tan, K. Liu, L. Liang, X. Cheng, X. Zhang, L. Zhang, D. Yue, RSC Adv. 6 (2016) 20198-20201.

[67] C. M. Brunette, S. L. Hsu, W. J. Macknight, N. S. Schneider, Polym. Eng. Sci. 21 (1981) 163-171.

[68] C. M. Brunette, S. L. Hsu, M. Rossman, W. J. MacKnight, N. S. Schneider, Polym. Eng. Sci. 21 (1981) 668-674.

[69] N. S. Schneider, R. W. Matton, Polym. Eng. Sci. 19 (1979) 1122-1128.

[70] B. Bengston, C. Feger, W. J. MacKnight, N. S. Schneider, Polymer 26 (1985) 895-900.

[71] L. Cuvé, J.-P. Pascault, G. Boiteux, G. Seytre, Polymer 32 (1991) 343-352.

[72] L. Cuvé, J.-P. Pascault, G. Boiteux, Polymer 33 (1992) 3957-3967.

[73] C. H. Y. Chen-Tsai, E. L. Thomas, W. J. MacKnight, N. S. Schneider, Polymer 27 (1986) 
659-666.

[74] C. Li, S. L. Goodman, R. M. Albrecht, S. L. Cooper, Macromolecules 21 (1988) 23672375.

[75] A. Siegmann, D. Cohen, M. Narkis, Polym. Eng. Sci. 27 (1987) 1187-1194.

[76] G. Maglio, R. Palumbo, F. C. Sepede, Polym. Bull. 32 (1994) 565-571.

[77] I. Krakovský, Z. Bubeníková, H. Urakawa, K. Kajiwara, Polymer 38 (1997) 3637-3643.

[78] I. Krakovský, H. Urakawa, K. Kajiwara, Polymer 38 (1997) 3645-3653.

[79] M. A. Hood, B. Wang, J. M. Sands, J. J. La Scala, F. L. Beyer, C. Y. Li, Polymer 51 (2010) 2191-2198.

[80] D. Tang, C. W. Macosko, M. A. Hillmyer, Polym. Chem. 5 (2014) 3231-3237.

[81] J. P. Sheth, A. Aneja, G. L. Wilkes, E. Yilgor, G. E. Atilla, I. Yilgor, F. L. Beyer, Polymer 45 (2004) 6919-6932.

[82] C. Carré, H. Zoccheddu, S. Delalande, P. Pichon, L. Avérous, Eur. Polym. J. 84 (2016) 759-769.

[83] O. Lamarzelle, P.-L. Durand, A.-L. Wirotius, G. Chollet, E. Grau, H. Cramail, Polym. Chem. 7 (2016) 1439-1451.

[84] V. Besse, F. Camara, F. Mechin, E. Fleury, S. Caillol, J.-P. Pascault, B. Boutevin, Eur. Polym. J. 71 (2015) 1-11.

[85] M. J. Elwell, A. J. Ryan, H. J. M. Grünbauer, H. C. Van Lieshout, Macromolecules 29 (1996) 2960-2968.

[86] M. J. Elwell, A. J. Ryan, Polymer 8 (1996) 1353-1361.

[87] A. J. Ryan, W. R. Willkomm, T. B. Bergstrom, J. T. Koberstein, C. C. Yu, T. P. Russell, Macromolecules 24 (1991) 2883-2889.

[88] A. J. Ryan, C. W. Macosko, W. Bras, Macromolecules 25 (1992) 6277-6283.

[89] H. Knoezinger, H. Krietenbrink, J. Chem. Soc., Faraday Trans. 71 (1975) 2421-2430.

[90] M. H. Healy, L. F. Wieserman, E. M. Arnett, K. Wefers, Langmuir 5 (1989) 114-123.

[91] V. Lachat, V. Varshney, A. Dhinojwala, M. S. Yeganeh, Macromolecules 42 (2009) 
7103-7107.

[92] J. M. Alia, H. G. M. Edwards, W. R. Fawcett, T. G. Smagala, J. Phys. Chem. A 111 (2007) 793-804.

[93] M. A. Phadke, D. A. Musale, S. S. Kulkarni, S. K. Karode, J. Polym. Sci., Part B: Polym. Phys. 43 (2005) 2061-2073.

[94] M. R. Padhye, A. V. Karandikar, J. Appl. Polym. Sci. 30 (1985) 667-673.

[95] J. Kim, M. M. Mok, R. W. Sandoval, D. J. Woo, J. M. Torkelson, Macromolecules 39 (2006) 6152-6160.

[96] C. L. H. Wong, J. Kim, J. M. Torkelson, J. Polym. Sci., Part B: Polym. Phys. 45 (2007) 2842-2849.

[97] M. M. Mok, J. Kim, C. L. H. Wong, S. R. Marrou, D. Woo, C. M. Dettmer, S. T. Nguyen, C. J. Ellison, K. R. Shull, J. M. Torkelson, Macromolecules 42 (2009) 78637876.

[98] J. Xu, W. Shi, W. Pang, Polymer 47 (2006) 457-465.

[99] J. M. Hsu, D.-L. Yang, S. K. Huang, J. Polym. Res. 6 (1999) 67-78.

[100] P. J. Van Ekeren, E. P. Carton, J. Thermal Anal. Calorim. 105 (2011) 591-598.

[101] J. A. Miller, S. B. Lin, K. K. S. Hwang, K. S. Wu, P. E. Gibson, S. L. Cooper, Macromolecules 18 (1985) 32-44.

[102] M. M. Mok, J. M. Torkelson, J. Polym. Sci., Part B: Polym. Phys. 50 (2012) 189-197.

[103] I. Yilgor, E. Yilgor, S. Das, G. L. Wilkes, J. Polym. Sci., Part B: Polym. Phys. 47 (2009) 471-483.

[104] I. Yilgor, E. Yilgor, I. Guclu Guler, T. C. Ward, G. L. Wilkes, Polymer 47 (2006) 41054114.

[105] J. P. Sheth, D. B. Klinedinst, T. W. Pechar, G. L. Wilkes, E. Yilgor, I. Yilgor, Macromolecules 38 (2005) 10074-10079.

[106] J. P. Sheth, D. B. Klinedinst, G. L. Wilkes, I. Yilgor, E. Yilgor, Polymer 46 (2005) 73177322. 
[107] D.-K. Lee, H.-B. Tsai, J. Appl. Polym. Sci. 75 (2000) 167-174.

[108] D.-K. Lee, H.-B. Tsai, R.-S. Tsai, P.-H. Chen, Polym. Eng. Sci. 47 (2007) 695-701.

[109] J. T. Garrett, R. Xu, J. Cho, J. Runt, Polymer 44 (2003) 2711-2719.

[110] H. S. Lee, Y. K. Wang, W. J. Macknight, S. L. Hsu, Macromolecules 21 (1988) 270-273.

[111] H. S. Lee, Y. K. Wang, S. L. Hsu, Macromolecules 20 (1987) 2089-2095.

[112] G. J. E. Biemond, J. Feijen, R. J. Gaymans, J. Appl. Polym. Sci. 105 (2007) 951-963.

[113] G. J. E. Biemond, K. Braspenning, R. J. Gaymans, J. Appl. Polym. Sci. 107 (2008) 21802189.

[114] G. J. E. Biemond, K. Brasspenning, R. J. Gaymans, J. Appl. Polym. Sci. 124 (2012) 1302-1305.

[115] T. A. Speckhard, P. E. Gibson, S. L. Cooper, V. S. C. Chang, J. P. Kennedy, Polymer, 26 (1985) 55-69.

[116] T. A. Speckhard, K. K. S. Hwang, S. L. Cooper, V. S. C. Chang, J. P. Kennedy, Polymer 26 (1985) 70-78.

[117] T. A. Speckhard, S. L. Cooper, Rubber. Chem. Tech. 59 (1986) 405-431. 